\title{
nature
}

\section{Trust and how to sustain it}

Against a background of declining public trust in traditional institutions, scientists must work to retain their high public-confidence ratings. There are warnings and lessons to be learned from the events of 2002.

f opinion polls are to be believed, scientists enjoy great public respect and trust. In an August Harris poll, Americans ranked 'scientist' as the most prestigious profession, edging out 'doctor', which had topped the list for the previous five years. In another Harris poll taken in November, $68 \%$ of respondents said they trust scientists to tell the truth - more than the number who trusted the president, and fifth behind teachers, doctors, professors and police officers.

But public trust in all professions, from judges to journalists, has dropped noticeably since a similar survey taken last year. And we don't need pollsters to tell us that faith in institutions, from the stock market to churches, has recently been under strain. In such times, scientists would do well not to take their favourable rating for granted. Things could easily take a turn for the worse. Two of the growth industries for scientists are biotechnology and defence, both of which are politically charged, and in the context of the war on terrorism, are now related. A protracted war in Iraq or a steep economic decline could erode public respect for scientists if they are identified with failing policies.

Another risk comes from pushing, or appearing to push, controversial practices opposed by large segments of the population, such as genetic manipulation of foods or stem-cell research. This is more than a question of who's 'right'. Too many scientists dismiss opposition based on emotion or differences in world-view, arrogantly believing that if the public is simply told the facts, they will fall in line. Researchers who work for profit-making ventures should be particularly careful, as their motives are more open to suspicion. In a poll taken in March for the British Royal Society, more than half of the respondents thought that science funding is becoming too commercialized, and said they wanted more influence over the research agenda. Scientists will keep the public's trust as long as they consider citizenship as well as scholarship.

A third threat comes from recent scandals, such as that involving physicist Jan Hendrik Schön's falsification of data (see page 728).
Scientific misconduct is rare and damages the image rather than the long-term substance of science. So far, these seem like isolated cases of misconduct, and the labs involved have reacted quickly and responsibly. But the Catholic church's more serious scandals can serve as a cautionary tale. Last year, $90 \%$ of people quizzed in a Harris poll said that they trusted the clergy to tell the truth; this has now fallen to $64 \%$. The public expects scientists, like priests, to have high standards. Not that researchers are saints or sages. But science is meant to serve truth and the advancement of knowledge above self-protection or profit. Putting self-interest first is precisely how the church got itself into trouble. Scientists and their institutions need to react promptly to misconduct, even though the burdens of doing so are usually onerous.

Trust in science could also be diminished by people who exploit scientific uncertainty for political ends, such as by casting doubt on the evidence for global warming or evolution. A few 'sceptics' appearing on TV can confuse a public that expects monolithic truth from science. All that scientists can do is explain that scientific 'truth' keeps changing in the light of new evidence, and provide the bigger picture.

Scientists are constantly exhorted to do a better job of explaining, and sometimes selling, what they do to the public. And well they should, as long as the public-relations campaigns stay honest and don't veer into deceit. It may not be the researchers themselves who do the deception, but the organizations they work for, such as biotech companies that tout gene therapy as the answer to all of life's problems.

In societies where market values increasingly trump all others, where advertising and spin are pervasive, and where broadcast news — the main source of information for most people — is increasingly partisan, the public has fewer places to turn to for objective, neutral information. Science can be of great service to society here. Out of more than just self-interest, then, scientists should be careful not to trade away the public trust, or allow others to trade it away for them.

\section{Managing CERN's industries}

\section{Europe's huge particle-physics laboratory is now in need of both brilliant science and outstanding management.}

ollowing the appointment of Robert Aymar as the new director general of the European particle-physics laboratory CERN (see page 721), the laboratory has a good chance of re-establishing the full confidence of its member states following recent budgetary problems. Aymar is known for taking as much pleasure from the good management of physics as from the physics itself. And good management will be paramount between now and 2007, as the world's next major accelerator, the Large Hadron Collider (LHC), is constructed and launched. Magnets are being tested, the gigantic detectors are being constructed, and the massive computational analysis based on Grid supercomputer networks is being developed. Through all of these projects, it will be essential to maintain confidence in what is, in effect, industrial production of the key LHC components.

The closure of the Large Electron-Positron collider (LEP) in 2000 was the toughest and most controversial decision made by the current director general, Luciano Maiani, given the apparent signatures of the long-sought Higgs boson from the LEP detectors. Subsequent analysis has shown those signatures to be less suggestive than was originally thought. The Large Hadron Collider will probably either reveal the Higgs for what it is or plunge high-energy physics into a conceptual crisis if it can't be found.

Despite the absence of a large accelerator, CERN does not have to wait until 2007 to accomplish strong physics. Its smaller facilities have recently created antihydrogen, definitively measured CP violation a still mysterious asymmetry in particle decays - and observed a crucial state of nuclear matter in which the quarks and gluons that make up neutrons and protons become 'deconfined'.

To continue these programmes and install the LHC will require tough decisions as obstacles inevitably arise. Aymar will be tested to his limits, but cannot do his job single-handedly. Others in CERN's team will have to earn their laurels not only by excellent experimentation, but also by first-rate project management. 